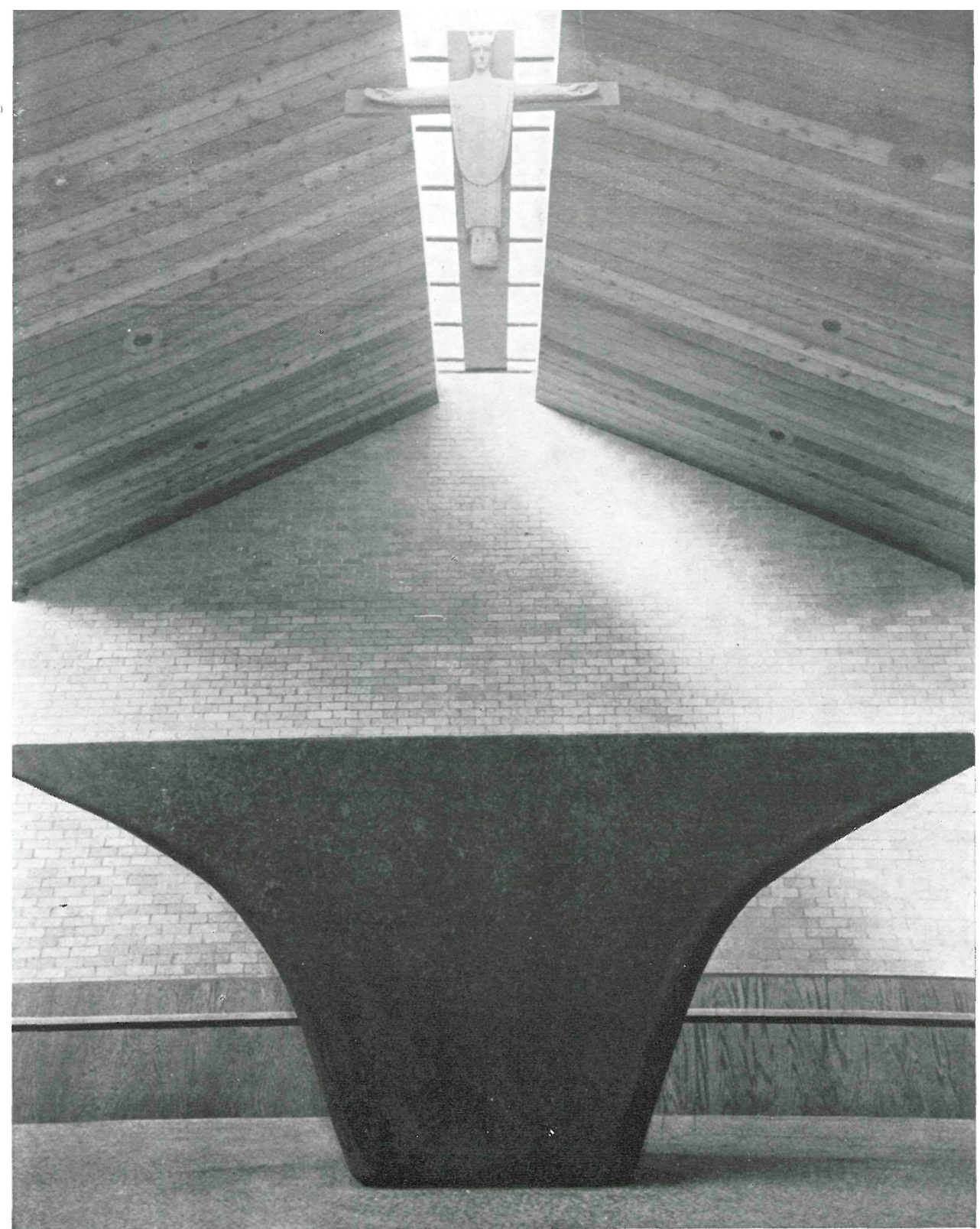

\title{
iglesia episcopal de Santo Tomás
}

JOHN PEKRUHN, arquitecto

148.77

Esta iglesia, situada en la localidad de Gibsonia (Pennsylvania), está emplazada en una zona de $4 \mathrm{Ha}$ que serán urbanizadas en el futuro; la nave tiene una capacidad suficiente para 200 personas, disposición en planta rectangular de $12,20 \times 24,40$ metros y una altura de 6,10 metros.

El edificio es un modelo de iglesia moderna y funcional.

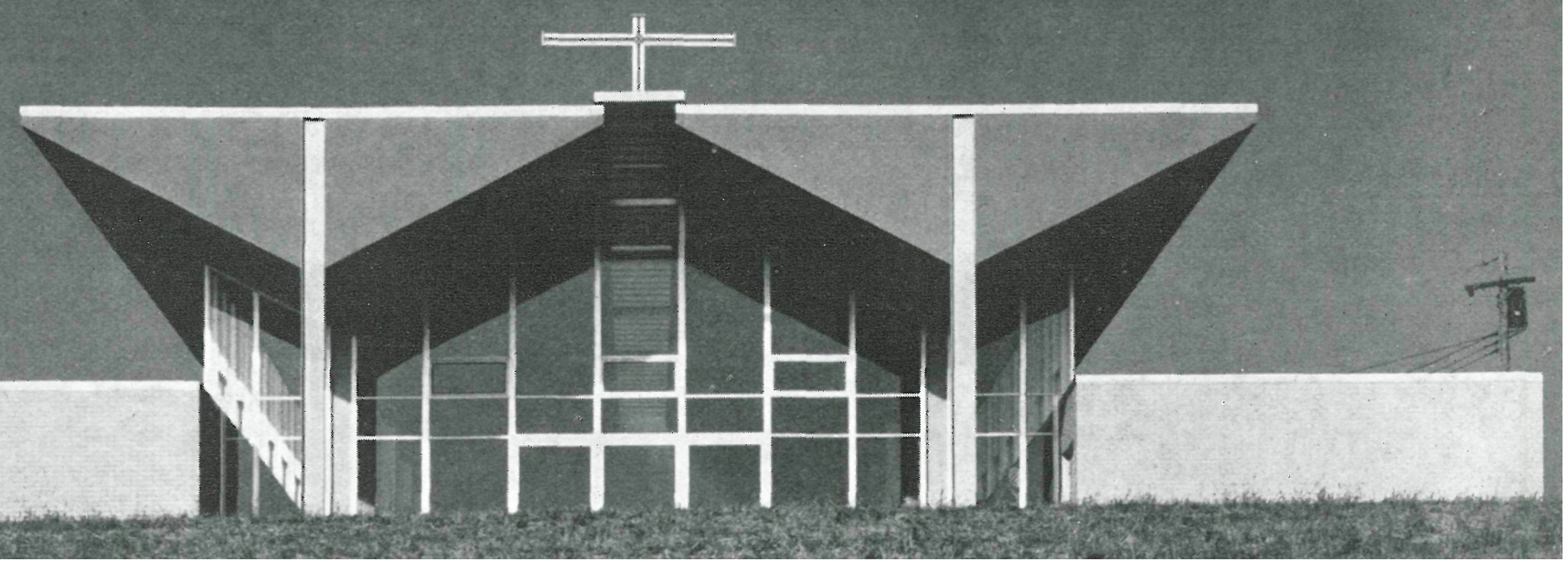




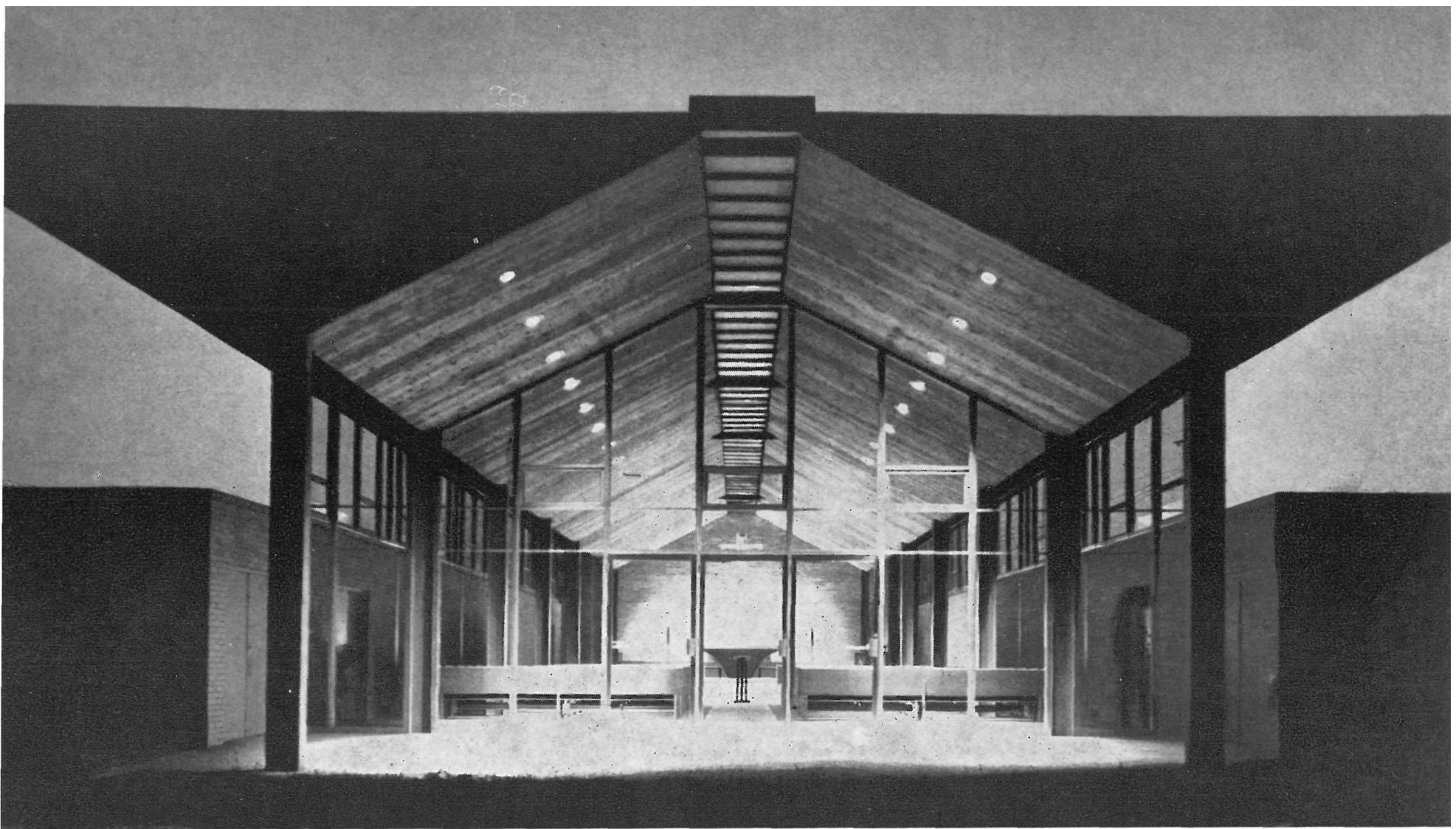

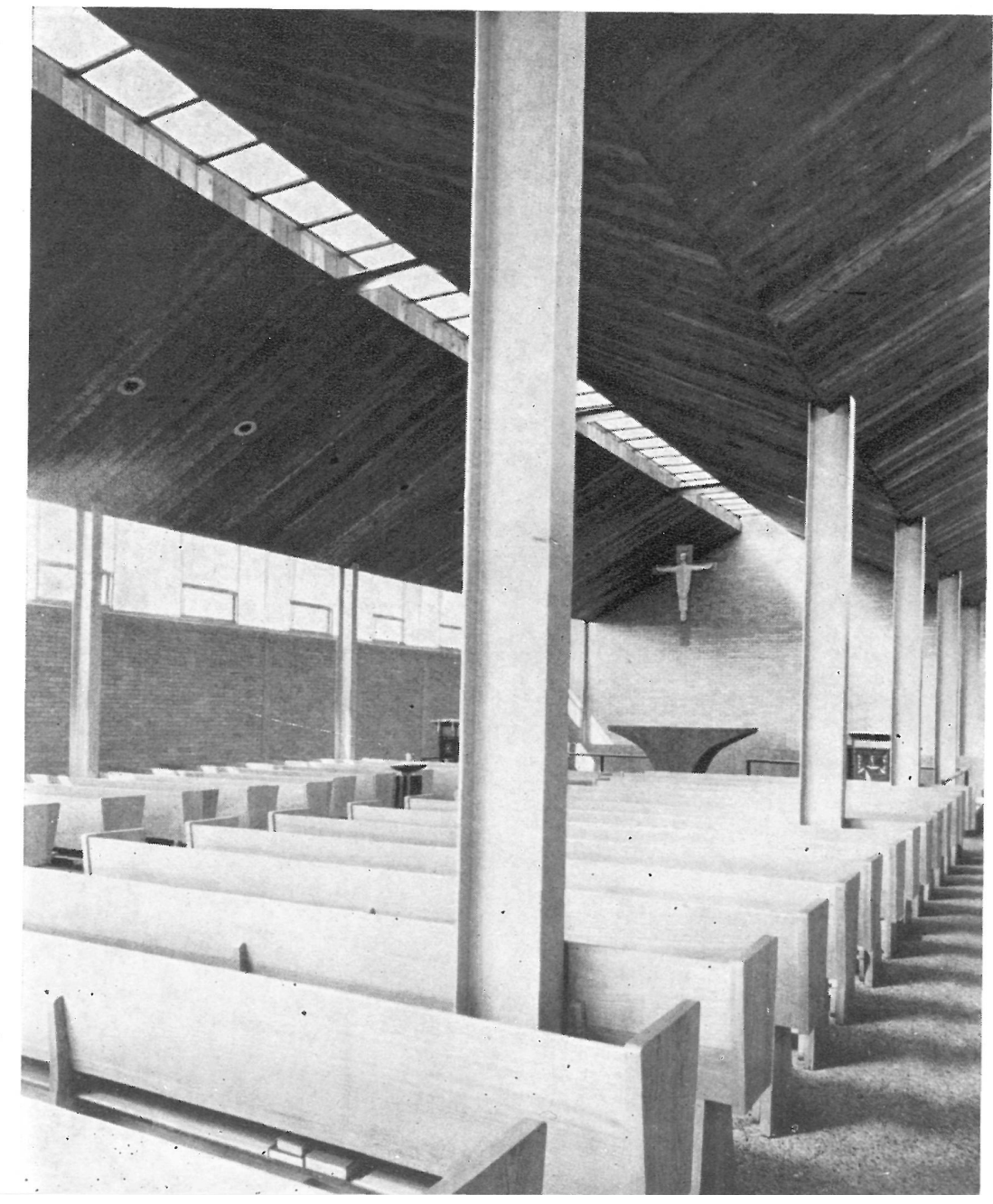

La nave se halla cubiert. por una doble hilera de estructuras triangulares ocultas por el entablado del techo, descansando todo este armazón sobre columnas sencillas constituidas por elementos de acero en doble $\mathrm{T}$ descubiertos. Esta composición produce un efecto de dinámico equilibrio y ligereza espacial, que no se hubiera alcanzado si estos elementos se hubieran unido convencionalmente.

La nave, amplia y bien iluminada, crea con estos efectos un adecuado ambiente para la adoración y el recogimiento. Al entrar, las principales líneas de la estructura conducen directamente hasta el retablo mural, el altar y el Cristo que preside desde la altura toda la iglesia.

La iluminación natural se encuentra previ. soramente dispuesta, ya que el intradós de las cerchas está inclinado de tal forma que el flujo básico de luz cenital puede entrar a través de las cristaleras iluminando claramente todas las partes de la nave. La luz artificial está también perfectamente diseñada por medio de dos hileras de puntos incandescentes incrustadas en el techo, que proporcionan una iluminación perfecta durante las horas de oscuridad; además, las cristaleras que forman las puertas de entrada y las situadas en el centro del techo producen un gran efecto de buena iluminación y permiten ver toda la iglesia tanto durante el día como durante la noche. 


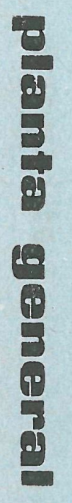

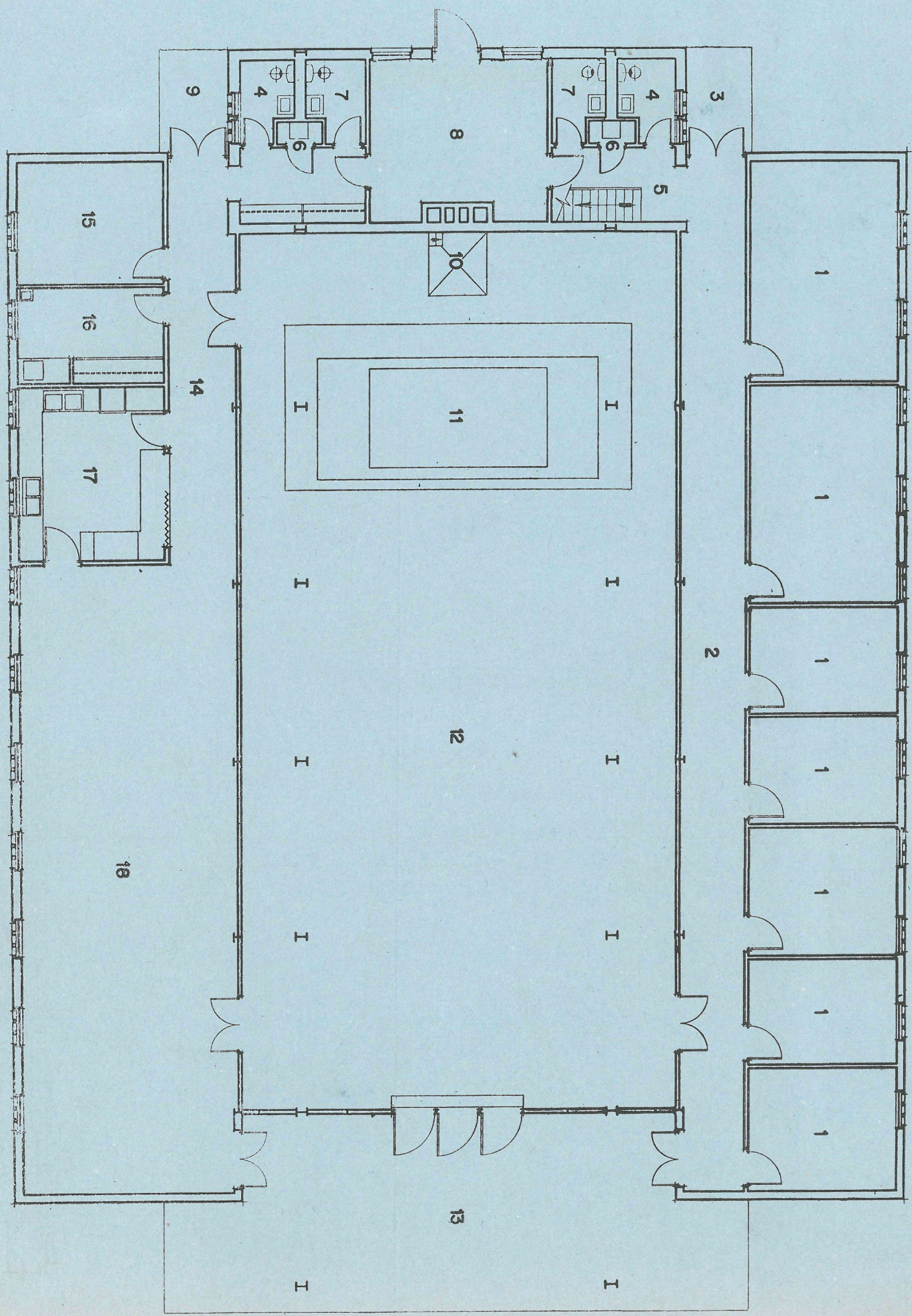




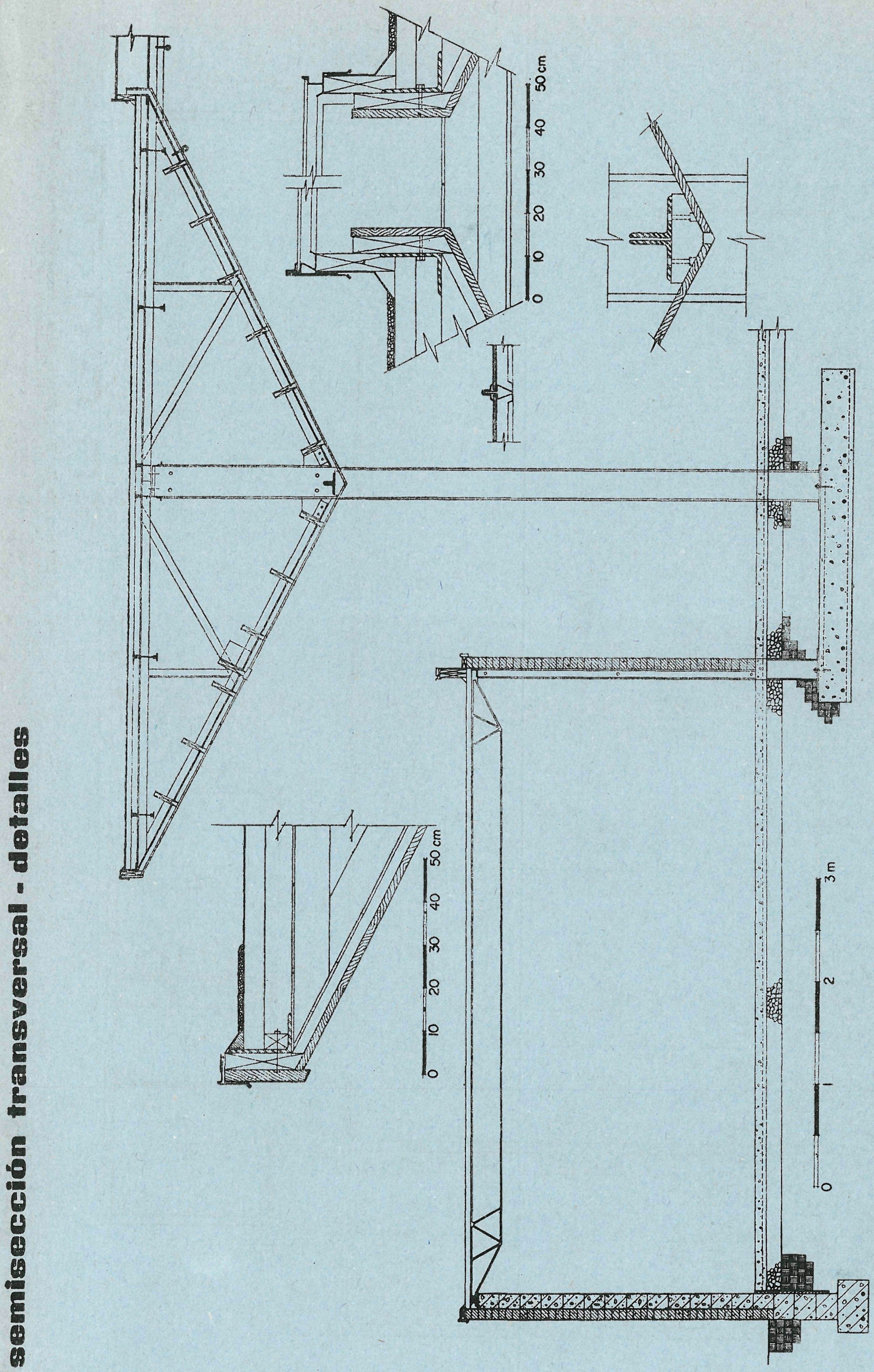




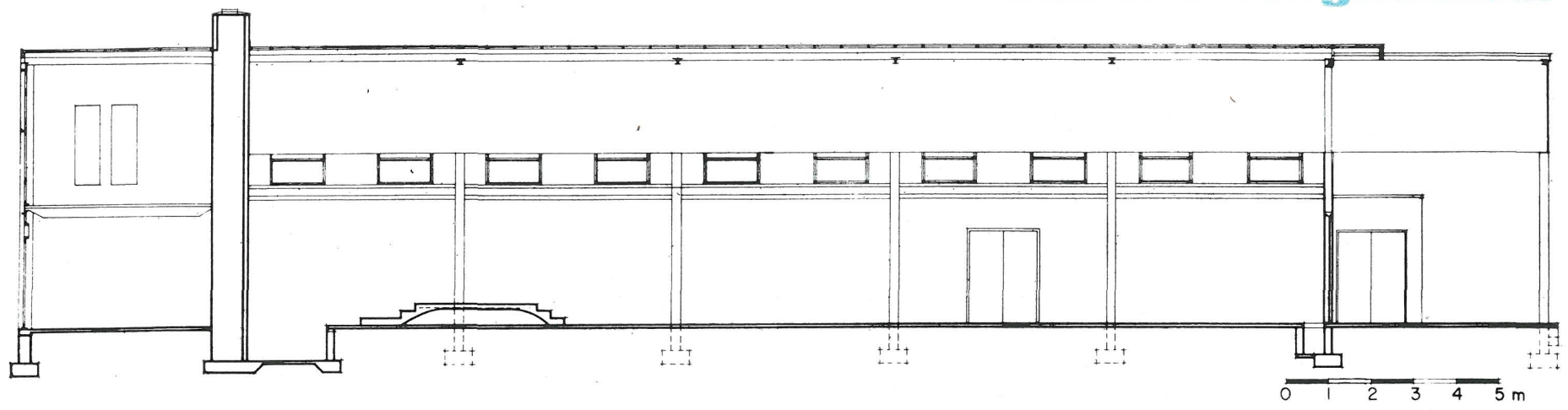

Respecto al interior, hemos de decir que los ornamentos litúrgicos de que consta fueron diseñados por dos escultoras pertenecientes a la Congregación y que contribuyen a dar una fuerte pincelada de vitalidad al interior de la nave. Janet de Coux -responsable de la decoración interior-diseñó el altar, compuesto por un bloque tablado de diorita negra, así como el Cristo que preside la nave, esculpido en madera de arce y colocado sobre una cruz pintada. Eliza Miller diseñó el púlpito y el atril, ambos realizados con acero negro recubierto por esmalte protector, así como la pila bautismal, que consta de la taza esmaltada, con remate de bronce y pedestal de madera de nogal.

Los materiales empleados en esta iglesia fueron escogidos de tal forma que presentaran las mejores y más apropiadas características. La superficie superior de las formas triangulares está cubierta por un tejado de cinco capas de 5 cm de espesor cada una y losetas de yeso apoyadas en viguetas de acero formando nervaduras abiertas; estas formas están cubiertas por un tablazón a base de chapas de madera de cedro con un espesor de 2 centímetros.

Fotos: MARC NEUHOF
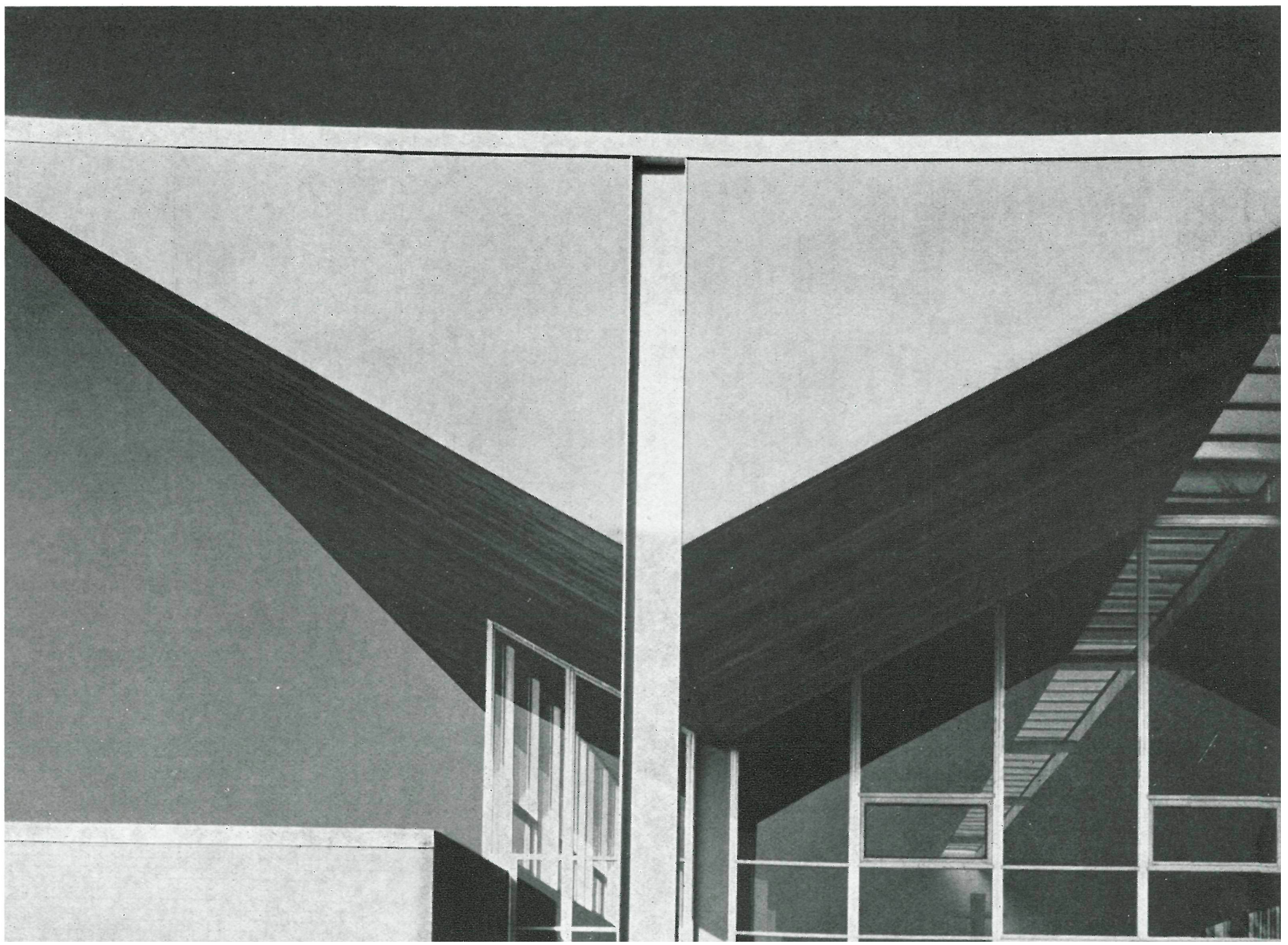


\section{detalles ponstructivos}

El suelo es de hormigón en masa, y tanto el interior como el exterior de los muros son de ladrillos corrientes. Los tabiques de separación internos son de madera plastificada, así como las puertas interiores, que son de madera enrasada, mientras que las vidrieras de las ventanas y las que forman las puertas de entrada tienen dos cercos de aluminio. Por lo demás, durante el invierno está asegurada una magnífica calefacción por medio de un sistema muy completo que funciona a base de quemadores de gas.

Esta construcción, además de la nave de la iglesia, comprende una serie de instalaciones secundarias propias de este tipo de edificios, tales como siete clases, situadas flanqueando la iglesia y la sacristía, cocina, salas para reuniones y estudios, etc., situadas al otro lado de la estructura. Todo esto hace de esta iglesia un moderno edificio perfectamente dispuesto para el culto y para la labor social propia de la Iglesia.

\section{ve ntama}

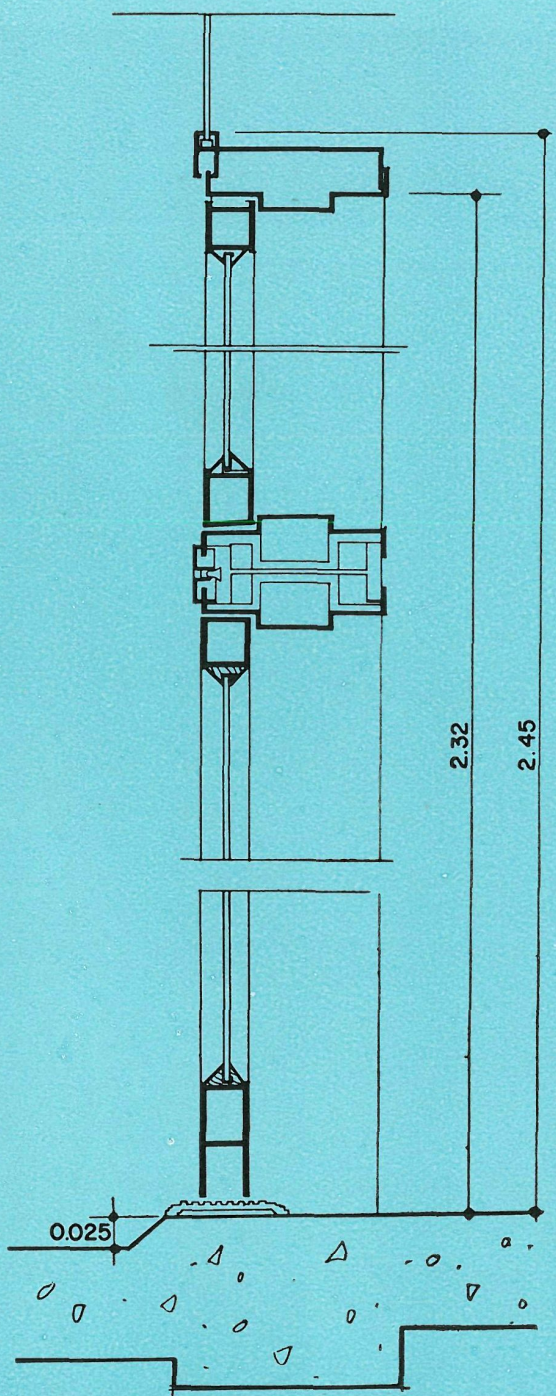

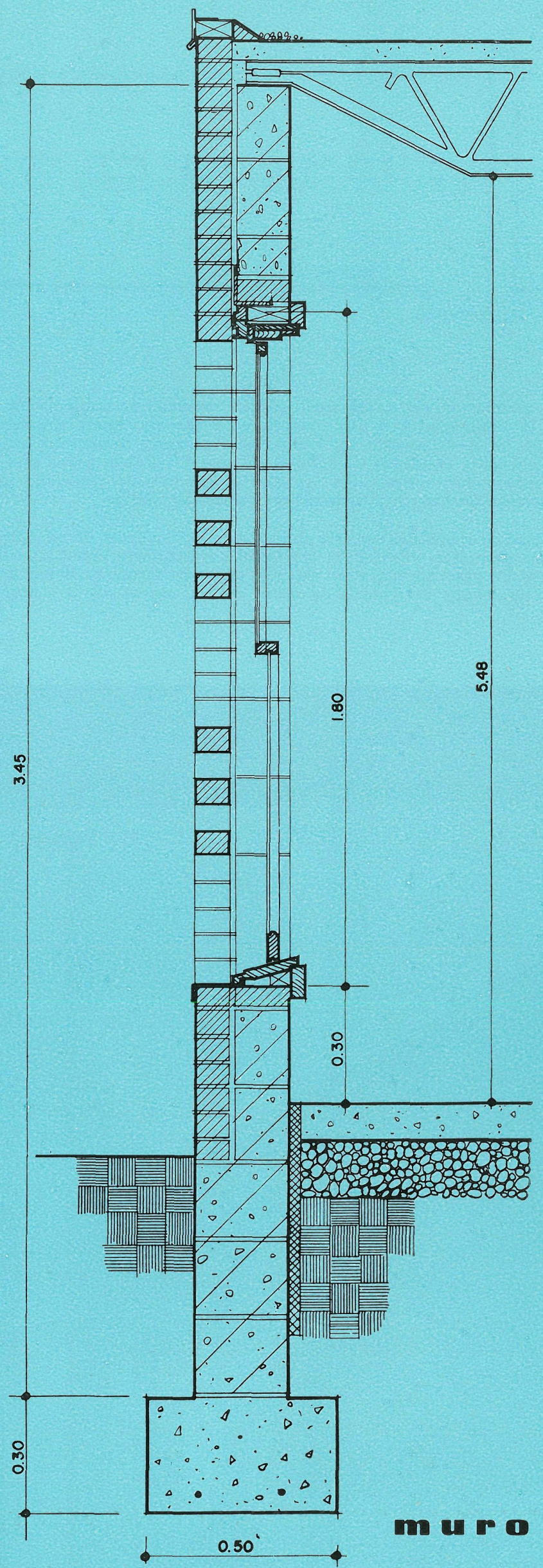

